\title{
A PRODUÇÃO DO ESPAÇO URBANO EM VITÓRIA-ES AO LONGO DA PRIMEIRA REPÚBLICA ENTRE DISCURSOS E INTERESSES, “FALSOS PROBLEMAS” AMPARAM AS TRANSFORMAÇÕES NA “CIDADE PRESÉPIO
}

\author{
Vinicius Francisco Marchese * \\ Universidade Federal do Espírito Santo
}

Resumo: 0 presente artigo visa interpretar a produção do espaço urbano em Vitória ao longo da Primeira República, momento de importantes mudanças no Brasil e, consequentemente, no Espírito Santo. Completam tal conjuntura a ascensão do Presidente de Estado Muniz Freire e seus ideais positivistas de modernização, somados a defesa dos interesses agroexportadores sediados na capital. Este personagem foi responsável por dar início a uma série de obras e projetos na antiga "Cidade Presépio", com o intuito de dotá-la de uma capitalidade que, naquele momento, ainda era incipiente. Dessa forma, serão analisados alguns de seus discursos e práticas, propagadores de "falsos problemas" utilizados como justificativas para processos de mercantilização da cidade, travestidos para o grande público como meras ações focadas no melhoramento urbano da capital. Palavras-chave: Vitória. Muniz Freire. Novo Arrabalde. Capitalidade.

THE PRODUCTION OF THE URBAN SPACE IN VITÓRIA-ES THROUGHOUT THE FIRST REPUBLIC. BETWEEN SPEECHES AND INTERESTS, "FALSE PROBLEMS" ENDORSE TRANSFORMATIONS IN THE “CIDADE PRESÉPIO”

Abstract: This article aims to interpret the production of the urban space in Vitória throughout the First Republic, a time of important changes in Brazil and, consequently, in Espírito Santo. These conditions are complemented by the rise of the President of State Muniz Freire and his positivist ideals of modernization, together with the defense of the agro-export interests based in the capital. This character was responsible for starting a series of works and projects in the old "Cidade Presépio" with the intention of endowing it with a capitality that, at the moment, was still incipient. In this way, some of his discourses and practices, propagators of "false problems" used as justifications for the commercialization processes of the city will be analyzed, transposed to the general public as mere actions focused on the urban improvement of the capital.

Keywords: Vitória. Muniz Freire. Novo Arrabalde. Capitality.

LA PRODUCCIÓN DEL ESPACIO URBANO EM VITÓRIA-ES EM TODA LA PRIMERA REPÚBLICA. ENTRE DISCURSOS E INTERESES, "FALSOS PROBLEMAS" APOYAN TRANSFORMACIONES EN LA "CIDADE PRESÉPIO"

Resumen: Este artículo tiene como objetivo interpretar la producción del espacio urbano em Vitória a lo largo de la Primera República, una época de cambios importantes en Brasil y, em consecuencia, em Espírito Santo. Estas condiciones se complementan com el ascenso del Presidente del Estado Muniz Freire y sus ideales positivistas de modernización, junto con la defensa de los intereses agroexportadores radicados en la capital. Este personaje fue el encargado de iniciar una serie de obras y proyectos en la antigua "Cidade Presépio" con la intención de dotarla de un capital que, de momento, aún era incipiente. De esta manera, se analizarán algunos de sus discursos y prácticas, propagadores de "falsos problemas" utilizados como justificación de los procesos de comercialización de la ciudad, transpuestos a la ciudadanía em general como meras acciones enfocadas a la mejora urbana de la capital.

Palabras clave: Vitória. Muniz Freire. Novo Arrabalde. Capitalidad. 
Introdução

O estado do Espírito Santo, Brasil, chega ao período da Primeira República sem uma referência urbana concreta para seu território e organização político-econômica, de acordo com os preceitos que floresciam. As principais cidades existentes, além de se mostrarem "atrasadas" frente aos anseios trazidos pelo novo regime, ainda se apresentavam desarticuladas em relação à capital e subservientes a estados vizinhos. Todavia, noções que se vinculavam a temática da urbanização e seu possível elo com o imaginário de "progresso" e de "modernidade", aparentes promotores de autonomia e riqueza, adquiriam vulto, ressoando entre as classes políticas locais naquilo que Ferreira, Quintão e Araújo (2018) chamaram de urbanismo oligárquico, o qual se baseava, dentre outros aspectos, na afirmação regional da cidade e na reinvenção de seu espaço público e suas formas de apropriação. Todos esses princípios se encontravam direcionados à produção de um urbano que privilegiaria determinados grupos no controle estadual, apesar destes esbarrarem em uma série de empecilhos à implantação de seus ideais.

Consequentemente, tais empecilhos se sobressaiam na então Cidade Presépio, alcunha concedida, no início do século XX, à Vitória, capital do Espírito Santo. A denominação, ainda empregue com apreço por capixabas ao se referirem a cidade, surge com o intuito de evidenciar o contraste paisagístico formado por sua configuração naturalmente limitada, entre maciços rochosos e a baía, bem como a presença de logradouros ocupando a encosta e iluminados ao entardecer, dando origem a um cenário sui generis à época (MONTEIRO, 2008). Logo, tal denominação alude e será aqui utilizada a fim de enfatizar esse passado urbano visto como "limitado" pelas lideranças do período, não só em termos naturais, mas também em meio a outros aspectos e interesses, especialmente os econômicos. Isto tornaria Vitória alvo de uma série de investidas governamentais no decorrer da Primeira República, com a finalidade de "(...) fomentar o protagonismo econômico da capital, caminhando a braços dados com sua centralidade política" (FERREIRA; QUINTÃO; ARAÚJO, 2018, p. 93). Desta forma, fica claro que a Cidade Presépio já desempenhava o papel de núcleo político estadual, principalmente por abrigar uma classe de agroexportadores que havia adquirido substancial participação nos rumos da história capixaba, mas que não via essa importância se refletir em seu viés econômico no período.

Por isso, presidentes do Estado, tendo destaque a figura de José de Melo Carvalho Muniz Freire (18611918), debruçaram-se na (re)estruturação urbana da capital, visando materializar novos espaços de produção, consumo e moradia que aglutinassem uma capitalidade ${ }^{1}$ também econômica, ainda incipiente em Vitória. Desse modo, ao longo do primeiro mandato de Muniz Freire (1892-1896), ponto central das análises e do recorte temporal aqui realizado, foram propostas e, até certo ponto, executadas, obras e projetos responsáveis por dotar a cidade da infraestrutura que se julgava necessária à sustentabilidade de um urbano que vinha de encontro aos anseios oligárquicos. Dentre estes projetos, destacam-se uma série de obras e empreendimentos no antigo centro da capital, somando-se ainda a elaboração do Novo Arrabalde, tratando da expansão de áreas em Vitória, conquistadas junto à baía, por meio de aterros.

Essas intervenções no espaço, promovidas por agentes, majoritariamente, públicos, mas que apresentavam forte vínculo com o setor cafeicultor, aparentam expor laços com, ao menos, dois processos, aqui tratados como hipóteses. 0 primeiro se refere à importância dos discursos políticos, mas não somente a eles, enquanto promotores de falsos problemas, amparando o desenvolvimento de uma urbanização que tornar-se-ia carregada de particularidades consonantes com interesses escusos que se concretizavam na capital. Assim sendo, na qualidade de falsos problemas, de acordo com Bolaffi (1979, p. 40), compreendem-se as questões que ocorrem dentro de uma perspectiva na qual "(...) a ideologia mascara os problemas do real e os substitui pelos falsos problemas. Isto é, formulamse problemas que não se pretende, não se espera e nem seria possível resolver, para legitimar o poder e para justificar medidas destinadas a satisfazer outros propósitos".

Já o segundo processo se encontra vinculado ao desenvolvimento de um ajuste espacial que se expressaria pela soma de políticas e práticas visando à mercantilização da então Cidade Presépio, seja a partir de atos como a reconfiguração do antigo centro de Vitória, seja a partir da confecção de um "novo arrabalde" dentro dos limites da capital, bem como a concomitante tentativa de se estabelecer uma reorganização territorial da economia capixaba. Neste sentido, cabe registrar que a expressão ajuste espacial é apropriada de Harvey (2006), o qual desenvolve suas abordagens dentro do capitalismo internacional contemporâneo e da ascensão do regime neoliberal. Por isso, em virtude deste artigo se referir a um viés geo-histórico pretérito ao construto intelectual do geógrafo, o uso da expressão será alvo de contextualização e/ou aproximação.

1 Por capitalidade se compreende "(..) a capacidade político-administrativa desempenhada por uma capital de carrear para si recursos e investimentos ao bem de seu desenvolvimento, ainda que, como resultado, impactos futuros indesejáveis possam ocorrer" (MENDONÇA; FREITAS, 2012, s/p). 
Ademais, é em virtude desse viés que se optou pela pesquisa básica-fundamental para a realização deste estudo, contando com metas que permeavam o campo exploratório e explicativo (PRODANOV; FREITAS, 2013). Nela, foi realizada uma revisão bibliográfica com ênfase em análises a respeito da conjuntura geo-histórica do Espírito Santo e sua capital no limiar da Primeira República, através de material disponível sobre o tema, com o propósito de formar um necessário arcabouço de dados secundários. Soma-se a isso a realização de pesquisas documentais, cuja interpretação contribuiu para ilustrar determinados argumentos que embasam as considerações aqui presentes. Neste ínterim, enquanto dados primários e respeitando o recorte temporal proposto, é dado destaque aos principais discursos proferidos por Muniz Freire no decorrer de seu primeiro mandato como Presidente de Estado.

Enfim, o objetivo deste estudo foi analisar a forma como se deu a gênese do urbanismo oligárquico no Espírito Santo, saindo do campo das ideias, no início da Primeira República, para a prática, nas décadas seguintes. Ao mesmo tempo, se objetiva expor uma crítica a visão urbana do período, permeada por apelos desenvolvimentistas e modernizantes que escamoteavam e amparavam os anseios da elite em busca de uma capitalidade, aparentemente, baseada na transformação de Vitória em prol de sua futura mercantilização. Isto posto, busca-se evidenciar as possíveis reais ambições por trás do desenvolvimento dessa capitalidade: seus discursos, promotores de falsos problemas, e suas ações, materializadoras de um "primitivo" ajuste espacial capixaba.

Vitória e o contexto capixaba no limiar da Primeira República

Cidade velha e pessimamente construída, sem alinhamentos, sem gosto, sem architectura, segundo os caprichos do terreno; apertada entre a bahia e um grupo de montanhas, não tendo campo para desenvolver-se sem a dependência de grandes despezas; mal abastecida de agua; com um serviço de illuminação á gaz duplamente arruinado, pelo estado do material e pela situação de sua empreza; (...) sem edifícios notáveis; repartições e serviços publicos mal accommodados á falta de prédios; sem um theatro, sem um passeio publico, sem bons hospitaes, sem um serviço de limpeza bem organisado, sem um matadouro decente; desprevenida de toda defesa sanitária; necessitada de construir novos cemiterios devido á irrevogável comndenação dos actuaes; finalmente balda até de pessoal operario para os serviços ordinarios de estiva, de transportes, cargas e descargas de navios construcções, e todos os outros indispensaveis em qualquer centro populoso de menor atividade e importância commercial. (ESPÍRITO SANTO, 1896, p. 17)

O pronunciamento acima, longe de expor ao público a cidade ideal, refere-se à Vitória, capital do Espírito Santo, e pertence ao seu primeiro governante no período republicano brasileiro, responsável por dar início a uma série de intervenções no estado e, em especial, na cidade de Vitória: o advogado, jornalista e político, José de Melo Carvalho Muniz Freire. Sua fala, durante discurso de transição ao final de seu primeiro mandato, manifesta visível insatisfação com o panorama apresentado pela capital, revelando não somente alguns ideais urbanísticos que permeavam a conjuntura da época, como também possibilita inferir todo um projeto de "modernização" por ele elaborado, visando contornar o aparente atraso e limitação da capital.

Desse modo, ao longo dos dois mandatos de Muniz Freire (1892-1896 e 1900-1904) e com a implementação de muitos de seus projetos por políticos como Jerônimo de Souza Monteiro (1870-1933), governando entre os anos de 1908 e 1912, e Florentino Avidos (1870-1956), Presidente do Estado de 1924 à 1928, têm-se início o beneficiamento de Vitória, para que ela assumisse o papel de núcleo econômico capixaba via setor de comércio e serviços voltados à exportação ${ }^{2}$. Preteritamente a essas sucessivas alterações, pode-se afirmar que a capital e seu entorno - ainda que centralizando o aparelho político-administrativo local -, ficaram relegadas frente à dinâmica capitalista assumida pela Região Sudeste no princípio da República brasileira, marcada e organizada no espaço pela monocultura do café, apesar de o Espírito Santo já se encontrar abarcado pela expansão da fronteira agrícola proveniente das regiões do Oeste Paulista e do Vale do Paraíba. Por outro lado, se tal conjuntura, ainda que pretérita ao momento republicano no país, não dinamizou de forma direta e imediata a economia da capital, ela teve profundos reflexos na estrutura populacional capixaba no decorrer do século XIX. De acordo com Almada (1993), a chegada de fluminenses impulsionados pela decadência produtiva das lavouras do Rio de Janeiro (RJ), associada aos mineiros recémchegados da Zona da Mata Mineira (MG), foi responsável - mais até que a imigração europeia - por expandir a fronteira agrícola no estado, interiorizando este processo que veio a se concentrar ao Sul do Rio Doce, em especial, no Vale do Itapemirim.

2 Neste ponto, cabe registrar que, anteriormente, o destaque econômico ficava a encargo das cidades de Cachoeiro de Itapemirim - devido a cafeicultura cuja produção era escoada pelo Estado do Rio de Janeiro, ao Sul - e, em menor medida, pela cidade de São Mateus - grande produtor de farinha de mandioca e importante porto escravagista, com economia atrelada ao Estado da Bahia, ao Norte. 
Soma-se a isso o fato de o Espírito Santo alcançar tal período sem ter formado em seus quadros uma classe de empreendedores aos moldes dos centros dinâmicos de comercialização, ou de entrada/saída de mercadorias, como os já existentes no Brasil. Neste sentido, Marchese (2017, p. 86) sentencia que os protagonistas da história capixaba no limiar da Primeira República compunham uma estrutura social baseada, em grande parte, por “(...) uma burguesia incipiente, uma elite débil e um governo míope". Tal fala revela as características que cada um destes estratos assumia, sendo compostos por uma "burguesia incipiente" devido à sua própria realidade, ainda regida pela busca por se reverter a inércia e a dependência passadas. De certa forma, tal quadro, a ser revertido, é fruto de particularidades geo-históricas locais, acrescidas a uma elite capixaba "debilitada" politicamente por não possuir peso representativo junto a capital federal. Nesse ínterim, essa mesma elite, constituinte do governo capixaba, deixava antever sua "miopia" ao "remar de acordo com a maré", ou seja, de acordo com os interesses circunscritos ao café e as decisões firmadas pelo Governo central (MARCHESE, 2017).

Portanto, essa "miopia" se manifesta, nos curto e médio prazos, por não haver uma ruptura da dependência cafeeira, ou a busca por novos setores e arranjos produtivos que incluíssem no desenvolvimento estadual o restante do território e, em particular, a capital. 0 que se observa com maior clareza no período republicano é uma mudança na organização territorial da economia capixaba, pois, conforme a visão das elites assumia contornos mais nítidos ao se materializar em um projeto de fortalecimento da capitalidade de Vitória, o território capixaba passava a contar não mais com uma organização baseada em seus extremos, norte e sul, mas com uma organização radial, cujo centro tomava por base a antiga "Cidade Presépio" e os interesses oligárquicos ali presentes.

Isto posto, Vitória começará a estabelecer um papel de integração regional, mas não necessariamente colocarse-á como um centro produtor no stricto sensu do termo. De certo modo, isso é compreensível ao se notarem duas questões: a primeira corresponde às dimensões da capital e seus aspectos naturais limitantes e/ou portadores de possibilidades outras, diferentes das quais e para as quais este território foi conduzido; em segundo plano, a forma de empreendedorismo urbano escolhido pelos agentes de produção do espaço, visando fortalecer sua capitalidade. Neste sentido, é válido pontuar que essa escolha se deu a partir de duas frentes de atuação, as quais correspondiam a: 1) foco na "reinvenção" do antigo centro de Vitória e do modo de vida de seus habitantes via alterações na paisagem construída da cidade, com o intuito de facilitar o desenvolvimento capitalista (FERREIRA, 2016); 2) foco na "confecção" de novas áreas para a capital, conquistadas ao mar e dotadas de uma infraestrutura considerada "moderna", adequada ao setor de comércio e serviços. Logo, esse empreendedorismo urbano, pelos privilégios técnicos ofertados e por seu planejamento, pressupunha-se, tornaria tais espaços mais valorizados que os anteriormente existentes ao atraírem empresas e novos moradores, elitizando a porção urbana que surgiria.

Consequentemente, essas prerrogativas aparentam ter sido bem-sucedidas, deflagrando uma terciarização do trabalho in loco, algo similar ao exposto por Seabra (1987) ao abordar a capital paulista. Entretanto, algumas ressalvas devem ser feitas, tendo em vista que, enquanto São Paulo (SP) viu o setor terciário crescer no bojo das indústrias nacionais que ali se instalavam, a busca capixaba por uma urbanização/modernização de sua capital parece ignorar o setor secundário, estabelecendo o comércio e serviços como o principal vínculo ao setor primário, cafeicultor, realizado nas porções sulista e interiorana do território. Parte daí a noção assumida por Mendonça (2014) ao considerar a opção pela terra no Espírito Santo uma expressão de "atraso" na Primeira República, levando-se em conta se relegarem ao e no estado as atividades produtivas multiplicadoras e/ ou atividades mais dinâmicas. Acrescenta-se a isso a perspectiva, observável, de que a tradição cafeicultora e todo o seu aparato sócio-político-econômico, surgido em meados do século $X I X$, tenha, assim, tido a possibilidade de se manter neste e nos próximos períodos da história local.

\section{Muniz Freire e os interesses da classe agroexportadora}

A Primeira República ficou conhecida como o período no qual as oligarquias nacionais, especialmente às vinculadas ao setor primário da economia, consolidaramse no poder $^{3}$. No caso capixaba, essas oligarquias são personificadas por, ao menos, dois clãs familiares representativos de diferentes setores econômicos, apesar de ambos estarem atrelados ao café. De um lado, o clã dos Pinto Ribeiro, cujo expoente foi Muniz Freire, despontando no cenário político capixaba a

3 É nesse mesmo período que se propaga a prática do coronelismo, a qual se compreende como uma forma de coação e manutenção do poder (social, econômico e político) por parte de uma elite baseada na propriedade da terra e em atividades econômicas de cunho rural. Apesar de ser característica de zonas interioranas e pequenas cidades, este fenômeno ganhou expediente e acabou por se espalhar por outras localidades, como é o caso do Espírito Santo e das disputas políticas que ganhariam vulto no decorrer da Primeira República. Ademais, cabe registrar que, de acordo com Mendonça (2014, p. 66), o coronelismo "Ao constituir uma forma particular de manifestação do poder privado, com enorme capacidade de penetração na esfera pública, (...), significou na formação social brasileira a expressão do capitalismo de natureza patrimonial". 
frente do recém-criado Partido Republicano Construtor (PRC), responsável por refletir os interesses da nascente classe de agroexportadores da capital. De outro lado, as famílias de latifundiários sulistas, que deram origem a União Republicana - Partido da Lavoura (UR-PL), tendo o clã dos Monteiro como seu principal quadro.

No entanto, apesar de ambos, Pinto Ribeiro e Monteiro, apresentarem forte rivalidade política, trazendo para esse cenário uma série de outras famílias sob suas bandeiras e tendo dividido o período republicano capixaba a partir de certo revezamento no poder local, ora via eleições diretas de membros dos clãs, ora via apadrinhamento de candidatos, nota-se que, à frente do governo, estes apresentavam orientações alinhadas, as quais revelam, dentre outros princípios, a busca por dotar Vitória de um urbanismo oligárquico que os atendesse. Logo, essa aproximação nas práticas governamentais entre grupos que se colocavam como antagonistas na administração do Espírito Santo, demonstra muito mais uma questão de disputas com base em um "endereço geográfico", do que, necessariamente, disputas de cunho político, ou proposicional quanto ao futuro do desenvolvimento capixaba (MARCHESE, 2017).

No que tange a figura de Muniz Freire, este, mesmo antes de se tornar o primeiro Presidente do Espírito Santo, já se destacava enquanto político ativo, defendendo ideais como a liberdade de imprensa, o Estado laico, o federalismo e o liberalismo econômico. Contudo, sem desmerecer sua capacidade como estadista, vale lembrar que seus mandatos, em especial o primeiro, deram-se em uma fase inédita na história capixaba, contando com a expansão do café e a alta de seu preço. Tudo isso, consequentemente, aumentou a receita local, além do período da Primeira República ter proporcionado ao Estado vivenciar uma autonomia política antes desconhecida, por mais que ainda sofresse algumas limitações por parte do Governo Federal, mas abrindo o precedente de atribuir à esfera local todo o imposto vinculado às atividades de exportação (SANTOS, 2012).

Quanto ao aspecto econômico, Bittencourt (2006) observa a "café-dependência" capixaba argumentando que a receita do governo seguia os movimentos de "diástole" e "sístole" de seus preços internacionais, o que gerava, por sua vez, uma grande instabilidade às finanças públicas. Para a "sorte" de Muniz Freire, seu primeiro governo se deu em um momento de "diástole", fruto de anos, imediatamente anteriores, de alta do café, alavancando o orçamento capixaba de cerca de 500 contos no final do regime imperial para mais de 5 mil contos em 1896 (SALETTO, 1996).

Desse modo, com receita em caixa, Freire encampa um projeto que transformaria Vitória na materialização de seu ideal positivista: um importante centro comercial e financeiro inspirado no exemplo das ditas grandes nações e suas destacáveis "praças", congregando importância política e/ou comercial (ESPÍRITO SANTO, 1896). Por isso, a modernização da capital se concretiza através da construção de prédios públicos, passando pela abertura de novas vias, além da negociação de vários contratos para a realização de serviços de abastecimento de água, esgoto e iluminação pública. Adicionalmente, vale mencionar a incessante busca de Muniz Freire por construir uma ligação ferroviária com Minas Gerais, atraindo a economia do vizinho interiorano para o escoamento via portos capixabas, algo que o levou a mediar, junto à União, um projeto existente para o porto da capital.

Ademais, nota-se que os ideais "construtores" e sua reiterada associação com as noções de progresso não se davam por mero acaso ou nomenclatura partidária tendo em vista Muniz Freire liderar o Partido Republicano Construtor (PRC) enquanto seus rivais se encontravam associados à bandeira da "lavoura" - (SUETH; FRANCO, 2005), mas também se materializavam em ações via estreitamento de laços com o setor terciário na capital e o desenvolvimento de obras infraestruturais. Todavia, esses eram promovidos via propagação de falsos problemas, os quais tencionavam legitimação em meio ao grande público, facilitando se implantar os interesses oligárquicos na então Cidade Presépio.

\section{Os falsos problemas da Cidade Presépio}

Como se tornou prática corrente em várias localidades nacionais, com o início da Primeira República, os presidentes dos Estados trataram de imprimir na paisagem das parcas cidades existentes um aspecto que se mostrasse moderno e concatenado ao novo momento pelo qual o país passava (MONTEIRO, 2008). Tal prática objetivava atender a todos os públicos, tendo em vista que os discursos e relatórios governamentais se dirigiam às elites, enquanto outros símbolos, como a cidade e a paisagem urbana, por serem de fácil assimilação, foram utilizados para promover os novos valores e sensibilizar as massas com baixo nível instrucional (ROSTOLDO, 2011). Desse modo, obras de infraestrutura se proliferaram pelo Brasil, visando contornar um potencial "atraso" dos tempos imperiais, bem como o caráter colonial que muitas vilas e cidades ainda possuíam, ao mesmo tempo em que se tornavam anúncios do novo regime.

O caso do Espírito Santo não foi diferente. A Cidade Presépio também demandava, aos olhos da classe política, um quê de reforma, "(...) deixando de ser colonial, 
barroca e atrasada para se tornar republicana, eclética e moderna" (MONTEIRO, 2008, p. 95). Tais medidas ainda visavam atender ao apelo de que ela viesse a "(...) alcançar a hierarquia mais elevada em termos urbanos [mantendo-se] de fato em condição de superioridade política, econômica e administrativa em relação ao território circundante (...)" (MENDONÇA; FREITAS, 2012, $\mathrm{s} / \mathrm{p})$.

Portanto, fica patente, de acordo com os autores supracitados, que $o$ anseio por se apagar algumas das marcas urbanas do passado já figurava como prerrogativa para muitas das obras levadas a cabo em Vitória, referindo-se mais a uma questão de "identidade política" do que necessariamente fruto de imperativos para o pleno "funcionamento" da capital. Adicionalmente, há de se considerar certo "bairrismo centralista" de Muniz Freire em suas medidas, questão a qual o próprio foi acusado, ainda em vida, por seus opositores, devido a sua origem familiar se concentrar em Vitória e seus projetos se circunscreverem a essa cidade, em detrimento do antigo núcleo econômico estadual, Cachoeiro de Itapemirim, onde se encontravam os barões do café capixaba. A isso Quintão (2015, p. 49-50) traz pertinente argumento:

(...) a questão, além de político-partidária, revestiase de um caráter eminentemente regional: tratavase da imposição dos interesses da capital sobre os do interior, o que para Claude Raffestin traduz-se como a "mais-valia da capital", pois "[...] a capital, enquanto centralidade, concretiza materialmente, em vários sentidos, as grandes tendências da estratégia nacional" (2011: 172). Em questão, uma estratégia regional, ilustrada pelo plano de desenvolvimento da praça comercial e, incluído nele, o Novo Arrabalde, para atender ao interesse de consolidar em Vitória duas centralidades regionais: a política e a econômica.

Quanto a essa mais-valia da capital, defendida por Raffestin (2011), ela nos esclarece a tendência à capitalidade firmada por Muniz Freire ao longo de seus governos e seguida por políticos a posteriori. Este ideal reafirma a cidade de Vitória como o núcleo políticoeconômico desejado pelas oligarquias, bem como consagra e clarifica o "bairrismo" do então Presidente do Estado, travestido de planejamento territorial, na medida em que restringe "(...) o campo das intenções e das ações de outras regiões" (QUINTÃO, 2008, p. 129).

Logo, pode-se dizer que a mais-valia da capital já era gestada em e para Vitória no século XIX, naquilo que Santos (2005) viria a chamar de "pensamento político capixaba", baseado na superação do "mito fundador" e seu viés de "atraso regional"4. Contudo, este só vai sair do campo ideológico, da "cidade desejada" para a "cidade possível" (ROSTOLDO, 2011), no final deste século e primeira metade do $X X$, consubstanciando sua capitalidade a partir do empreendedorismo urbano e da reorganização territorial da economia capixaba, baseadas na conversão das rendas do interior para a Cidade Presépio, a qual assumia ares modernos. Ainda de acordo com Quintão (2008, p. 26), “(...) Vitória vai se apoiar na produção de seu interior para fortalecer seu poder econômico e, conseqüentemente, político, utilizando-se para tanto da ferrovia, a qual apresenta em si já um exercício de poder, na medida em que representa a imposição de sua vontade".

Durante estes eventos, cabe destacar que tal estratégia já figurava, mesmo que implicitamente, no discurso de posse de Muniz Freire ao seu primeiro mandato, em 1892:

\begin{abstract}
Nós temos a riqueza agricola esparsa na pequena propriedade, força poderosa quando concentrados os seus alamentos, mas insignificante quando dispersos como nós a temos.

É preciso que produzamos a riqueza geradora, a riqueza concentradora, a riqueza que colige todos os outros elementos de riqueza e os distribue por todo o organismo. Sabeis que refiro-me á riqueza comercial e á outra que d'ella [termo incompreensível] a capital. (ESPÍRITO SANTO, 1892, p. 4)
\end{abstract}

Sendo assim, estas estratégias, antes implícitas, ganham contornos mais nítidos ao longo dos próximos anos, por meio de discursos recorrentes que asseveravam a necessidade das obras no porvir. Discursos que também depreendiam a busca pelo apoio do corpo político, bem como soavam tal qual uma forma de sensibilização pública em prol dos ideais aos quais Muniz Freire representava, conforme se pode observar no trecho a seguir, o primeiro no qual o Presidente do Estado se refere diretamente à capital capixaba em um relatório de governo:

\footnotetext{
Uma grande preoccupação assalta a todos quantos se interessam delo engrandecimento do Estado, e medem o alcance e a influencia dos emprehendimentos que se acham em viabilidade - é que a execução de todos elles concorrerá seguramente para fazer da nossa capital um emporio commercial vastíssimo, e
}

4 Mendonça (2013) argumenta que o "mito fundador" capixaba ganha corpo em meio ao discurso político da elite capixaba no início da Primeira República. Baseado na noção de "atraso" e no passado recente do Espírito Santo, estes se apossaram de tais justificativas para alicerçar seus anseios político-econômicos e angariar o apoio necessário na preservação de determinados interesses junto ao território. Assim sendo, ainda de acordo com Mendonça (2013), este "mito fundador" molda o nascimento do Espírito Santo republicano e se fortalece com as várias formas de exploração ideológica destas noções nos discursos políticos, estimulando e sustentando este "signo do atraso regional". 
entretanto ella se acha completamente desaparelhada para sêl-o. A Victoria está fatalmente destinada a ser uma grande cidade, e no emtanto as suas condições topographicas não permittem que sem enormes despesas possamos adaptal-a a esse destino. Nós temos a felicidade de possuir uma das bahias mais pittorescas do mundo, segundo a versão de todos os viajantes, mas, em contraposição, no fundo d'essa tela admiravel da natureza, a incúria e a inepcia do homem assentaram a mais irregular e menos graciosa das cidades. (ESPÍRITO SANTO, 1894, p. 14-15)

0 tom, até certo ponto, alarmista quanto a urgência de se aparelhar e adaptar Vitória, uma "irregular e menos graciosa" cidade, para que esta alcançasse seu destino de "emporio commercial vastíssimo", deixa antever parte do que se tornaria simbólico no governo de Muniz Freire junto a então Cidade Presépio: a elaboração de um projeto visando "(...) estender as raias de seu campo de desenvolvimento" (ESPÍRITO SANTO, 1894, p. 15). Em parte, observa-se que esse ideal era respaldado pelo viés econômico atrelado ao setor terciário, mas também pairavam justificativas de cunho demográfico para a emergência e apoio às obras, como o próprio governante já havia mencionado em relatórios de 1893 e 1895, respectivamente:

Uma outra difficuldade porem tem se manifestado. Com o grande aumento de população que ha tido, a nossa capital está presentemente sob a crise da falta de habitações. Grandes massas de operarios se agglomeram em barracões para esse fim levantados, na carencia absoluta de outro meio de accommodação, porque o interior da cidade já regorgita de occupantes; é de temer que essa situação se prolongue, mormente si soffrermos qualquer invasão epidemica, e por isso solicito a vossa attenção para o caso. Opportunamente pretendo suggerir-vos uma medida que me parece efficaz. (ESPÍRITO SANTO, 1893, p. 22)

A Victoria carece de todos os serviços elementares indispensaveis a um grande centro populoso. Até ha pouco tempo muitas das necessidades que já agora se sente podiam passar desaporcebidas; mas com o augmento consideravel de população havido n'estes ultimos annos, algumas d'ellas estão determinando crises que o poder publico deve auxiliar a remover. As mais vexatorias de todas são a construcção de predios e o abastecimento sufficiente d'agua; esta ultima só se torna notavel em epocas excepcionaes, mas a primeira está actuando normalmente como uma grande causa perturbadora. Alem de contribuir para a carestia de vida, produsindo a elevação exagerada dos alugueis; de crear embaraços á execução de alguns melhoramentos, e impossibilitar outros, como sejam as demolições exigidas pelo interesse publico; a falta de habitações arreda continuamente d'entre nós bom número de actividades proveitosas, e torna tristemente precarias as condições de vida dos melhores collaboradores do nosso futuro, que são as massas operarias. (ESPÍRITO SANTO, 1895, p. 16)

Neste ínterim, alguns detalhes se mostram contraditórios ao que era exposto por Muniz Freire. Em primeiro plano se encontra o fato de que Vitória, no limiar da Primeira República, caracterizava-se como uma cidade composta por menos de dez mil habitantes, os quais eram plenamente comportados na Cidade Presépio, algo que minava a necessidade de se expandir a área urbana e criar novas habitações, bem como o discurso de esgotamento das terras urbanizáveis anexas ao antigo centro (FERREIRA, 2016). Não sendo este o real motivo, o único que se colocava plausível, possivelmente escamoteado pelo falso problema infraestrutural e demográfico, era o intuito de se estabelecer um urbanismo oligárquico que propiciasse a afirmação regional de Vitória, utilizando-se de preceitos da época, como o desejo de "embelezamento", racionalização e higienização da capital (FERREIRA; QUINTÃO; ARAÚJO, 2018). Inclui-se ainda o aparente anseio de se atender a interesses escusos de grupos e companhias, fomentando, especialmente, o setor imobiliário local. Por conseguinte, as mudanças que em breve tomariam curso eram legitimadas discursivamente por Muniz Freire, tornando-se um suposto legado de seu governo ao se traduzirem em uma herança político-ideológica seguida por seus sucessores. Uma espécie de "miopia freireana" ainda hoje observável no planejamento político e na organização territorial da economia capixaba ao privilegiar, substancialmente, sua capital (MARCHESE, 2017).

Outro detalhe que causa estranhamento em seu relatório de 1893 diz respeito ao fato deste reclamar da ausência de mão de obra em algumas das atividades governamentais no interior do estado, em particular na construção de novos ramais para as estradas de ferro. Logo, medidas promotoras do ingresso de trabalhadores nacionais em território capixaba foram anunciadas, o que leva a questionar quem compunha essas “(...) grandes massas de operarios [que] se agglomeram em barracões (...), porque o interior da cidade já regorgita de occupantes (...)" (ESPÍRITO SANTO, 1893, p. 22), bem como o motivo deste excedente de mão de obra da capital não ter sido redirecionado pelo governo para as obras que se encontravam carentes de profissionais. Questionamentos que, provavelmente, permanecerão sem respostas.

Porfim, em discurso de 1895, acima de ser considerada uma confissão de culpa, ou ineficiência no que tange ao seu primeiro mandato e a atenção dispensada aos 
contornos da capital, sua fala clarifica o que seriam seus próximos atos ao expor que a "medida eficaz" a qual pretendia sugerir, conforme anunciado ao Congresso Legislativo no ano de 1893, referia-se a um de seus últimos feitos, quando, ao final de seu primeiro mandato, cria a Comissão de Melhoramentos da Cidade mediante a Resolução n. 46 e contrata para presidir essa comissão o engenheiro sanitarista Francisco Rodrigues Saturnino de Brito (1864-1929). Assim, fica sob incumbência do engenheiro sanitarista realizar o levantamento topográfico de Vitória, identificando os principais e melhores pontos para se ampliar os domínios da capital em sua própria ilha. Um empreendimento que recebeu o nome de "Projecto de um novo arrabalde: dotado dos serviços de abastecimento dágua e de drenagem, para Vitória", ou, simplesmente, "Novo Arrabalde".

Mesmo assim, cabe salientar que estas obras tardaram a ocorrer, em virtude da estratégia político-administrativa traçada por Muniz Freire de, em um primeiro momento, optar pelo acúmulo de capital para, posteriormente, tocar seus projetos e empreendimentos. Isso fez com que seus ideais para a cidade se materializassem nas décadas seguintes, tendo destaque as justificativas de cunho sanitarista, apesar de contarem com um claro propósito de "(...) expansão territorial, dissimulada por razões de acessibilidade" (FREITAS, 2009, s/p). Tal justificativa só desaparece dos discursos, deixando explícitas as intenções por trás da modernização de Vitória, a partir dos governos de Jones dos Santos Neves (1943-1945 e 1951-1955), ao buscar desenvolver o aparato local em prol do sistema portuário ali existente. Em consequência, deste momento em diante, o lado pragmático do desenvolvimento se torna explícito nas ações governamentais, comprovando a noção de que "A cidade precisava, senão ser, ao menos parecer moderna" (FREITAS, 2009, s/p).

\section{O Novo Arrabalde e a mercantilização de Vitória-ES}

O Projeto do Novo Arrabalde consistia em uma série de obras infraestruturais cujo intuito seria o de acentuar o viés urbano da capital, sextuplicando a área ocupada da e na própria ilha de Vitória, além de torná-la o tão almejado núcleo econômico do estado. Algo que, pela magnitude do empreendimento e em virtude de todas as demandas exigidas pelo mesmo, só viria a se concretizar, conforme já mencionado, décadas mais tarde, mormente, por políticos que tornar-se-iam ferrenhos opositores de Muniz Freire ao final de sua jornada pública.

Com relação a magnitude do projeto, Saturnino de Brito (1996), vivenciando sua primeira experiência com expansão urbana, idealiza um novo núcleo para a cidade de Vitória a partir de uma série de aterros, especialmente na porção leste da ilha, margeando os inúmeros afloramentos rochosos e aglutinando as chácaras e lavouras ali existentes. Segundo Rostoldo (2011, p. 7), um dos intuitos do governo com o Novo Arrabalde era o de suprir a capital de edificações necessárias ao futuro que se almejava, tendo em vista certo déficit desta infraestrutura à época, em virtude da "(...) carência de capitais, o preço e a escassez de materiais, o esgotamento da área urbana e o aumento do valor venal dos poucos terrenos disponíveis".

Entretanto, Palacios (2007) contrapõe tais assertivas ao observar que as ações governamentais, em especial no antigo centro de Vitória, agora "reformado", contribuíram para um processo de segregação socioespacial, na medida em que uma série de condições foram impostas para seus habitantes, excluindo uma parcela da população via promulgação de sucessivos "códigos de posturas". Dessa forma, "(...) parte dos cidadãos [era segregada] dos benefícios dessa urbanização, senão primordialmente pelo poder aquisitivo dos mesmos e sua capacidade de se apropriar e usar o espaço urbano produzido, mas pela cor, estereótipo e/ ou relevância na hierarquia social que estes possuíam" (FERREIRA; QUINTÃO; ARAÚJO, 2018, p. 105). Em adição, encontra-se o fato de que o governo foi responsável por desencadear um processo de desapropriações gerador de uma crise habitacional sem precedentes na cidade, fruto da diferença entre as demolições promovidas e a capacidade de erigir novas moradias. Essas, por sua vez, foram construídas em pontos distantes de Vitória, afastando alguns grupos sociais e garantindo o espraiamento do tecido urbano (PALACIOS, 2007). Este e outros feitos (i.e. falsos problemas), inclusive, foram os responsáveis por fazer com que o governo tivesse que recorrer a construção de casas populares para contornar as consequências das medidas anteriormente adotadas (FERREIRA; QUINTÃO; ARAÚJO, 2018).

Mesmo assim, Muniz Freire ainda alimentava os ideais de empreendedorismo urbano, fazendo crer que, com estas obras, somadas a proximidade do Novo Arrabalde ao antigo centro da Cidade Presépio e o oferecimento de uma estrada adequada para o período e futuras demandas, estaria sanando aquilo que reiteradamente colocava como um dos principais empecilhos para o desenvolvimento de Vitória: a exiguidade dos terrenos disponíveis para uso e ocupação dentro da capital. Porém, a dimensão destes anseios, para que a "cidade desejada" se tornasse uma "cidade possível", demonstram o gigantismo do que era planejado para a primeira década republicana estadual, fato corroborado pelos extravagantes números apresentados por 
Saturnino de Brito (ROSTOLDO, 2011). Quanto a isso, Follador e Ferreira (2015, p. 87-88) expõem alguns dados, evidenciando parte das estratégias governamentais com o projeto:

\begin{abstract}
Com uma área de 3.293 .713 metros quadrados, muito superior à da capital original, dividida por 178 quarteirões e 2.129 lotes, esperava-se abrigar 15.400 habitantes, mais que dobrando a população da cidade. As larguras das ruas e avenidas, $21 \mathrm{e}$ 28 metros respectivamente, foram planejadas no sentido de garantir o maior número possível de cruzamentos entre os logradouros. O Novo Arrabalde, antes de constituir um projeto de melhoramento da cidade, criando um bairro saudável e convidativo, foi concebido pela lógica do mercado de terras tornandose um grande empreendimento imobiliário. Competia ao Estado, proprietário da maior parte do loteamento, negociar as vendas dos terrenos de forma direta com os compradores, reservando-se o direito de selecionar o momento ideal para a venda de parte dos lotes com valores diferenciados.
\end{abstract}

Em conformidade com os autores, concomitante ao avanço do projeto e suas obras, mesmo que paulatinamente no transcorrer da Primeira República, já era possível observar "a lógica do mercado de terras" acima do ideal de "melhoramento da cidade". Em suma, o que garantiria uma adequada reprodução da vida social e se destacava em parte dos discursos de Muniz Freire ao defender a modernização de Vitória, na medida em que se consubstanciava no espaço, passava a esboçar seus reais propósitos: a subordinação da vida urbana na capital à lógica mercantil via empreendimentos imobiliários. Por isso, o Novo Arrabalde passa a se configurar como um mero veículo formatado para garantir a mercantilização da cidade, se não via reestruturação urbana, tendo em vista a limitação topográfica da capital, agora via "confecção" de novas áreas conquistadas ao mar.

Ainda de acordo com os autores supracitados, adiciona-se o papel ativo do Estado na promoção das transformações verificadas, na medida em que este não se restringia à viabilização do projeto, pois também se colocava como "(...) proprietário da maior parte do loteamento, [negociando] as vendas dos terrenos de forma direta com os compradores, reservando-se o direito de selecionar o momento ideal para a venda de parte dos lotes com valores diferenciados" (FOLLADOR; FERREIRA, 2015, p. 88). Todavia, apesar do protagonismo público, já se observava a presença do capital privado, apropriandose de espaços e os modificando/especulando para o setor comercial e imobiliário (CAMPOS JÚNIOR, 1996).

0 destaque neste âmbito fica com a Companhia Brasileira Torrens, cujo contrato firmado com o governo em 1894 the garantia, em contrapartida pelos serviços prestados, uma série de privilégios, dentre eles a cessão gratuita de terrenos pertencentes ao Estado dentro da ilha de Vitória (CAMPOS JÚNIOR, 1996; MENDONÇA et al., 2009). Assim sendo, a particularidade existente nesta íntima relação, entre Governo do Estado e Companhia Brasileira Torrens, constitui a hipótese, levantada por autores como Campos Júnior (1996) e Quintão (2015), de que haveria um possível lobby desta junto a classe política da época, pressionando-a para que ocorresse um falseamento das vantagens existentes na capital em prol da implantação de projetos ali, em detrimento da antiga Vila do Espírito Santo, atual Vila Velha. Algo que permanece como incógnita, apesar dos indicativos existentes quanto a essa relação deveras escusa.

Em contrapartida, os pontos de estranhamento referentes a dinâmica assumida pelo Novo Arrabalde não se limitam às relações público-privadas. A própria confecção do projeto parece ter apresentado divergências entre o "desejo político" e a "realização técnica". Feito este que se nota em algumas situações nas quais Saturnino de Brito (1996) deixa clara sua oposição e/ou contrariedade quanto a parte das exigências de Freire e sua cúpula governamental, tendo destaque o que se refere à realização dos inúmeros aterros previstos para que a cidade pudesse ter seus domínios devidamente expandidos. Para tanto, Brito (1996) faz uso, inclusive, da opinião de outros especialistas neste tipo de empreendimento, com o intuito de advertir e, até mesmo, dissuadir o Presidente do Estado frente aos riscos e desvantagens que observava nesta empreitada.

No entanto, contrariando todos os avisos e apelos técnicos do engenheiro sanitarista, as obras são tocadas no decorrer da Primeira República. Em inúmeros estudos, Freitas (2004; 2009; MENDONÇA et al., 2009; MENDONÇA; FREITAS, 2012) destaca que tais medidas, independentemente dos motivos e justificativas oficiais concernentes às intervenções pelas quais a capital do Estado passou, demonstram a clara determinação política no que tange à implementação do Novo Arrabalde. Algo que denota um aparente sucesso no lobby capitalista junto ao poder público, conforme hipótese registrada.

Ainda corroborando com tais noções, de acordo com Monteiro (2008), a ocupação do Novo Arrabalde se efetiva na primeira metade do século $X X$, dotando a cidade de Vitória de um caráter estritamente residencial e estendendo seus domínios em direção às praias da região leste, enquanto a porção continental era marcada por uma série de conjuntos habitacionais em meio a grandes vazios preservados e destinados aos empreendimentos econômicos. Enfim, e resumindo o processo de desenvolvimento do Novo Arrabalde ao 
longo da Primeira República, Monteiro (2008, p. 74-75) retrata este momento e seus principais deflagradores do seguinte modo:

\begin{abstract}
Iniciada oficialmente por Muniz Freire, continuada por Jerônimo Monteiro e concluída por Florentino Avidos, a paisagem que deu fama à então quase desconhecida capital capixaba foi marcada não só pelo caráter administrativo e comercial, mas também por funções até então inexistentes ou inexpressivas na cidade, como a educacional e a de lazer - parques, teatros, cinemas. Revestindo o novo conjunto arquitetônico, a arquitetura eclética, impondo-se sobre um neoclássico tardio que nem chegou a se destacar, torna-se oficialmente o estilo-padrão, passando a configurar remodelações da antiga vila - como a igreja de São Tiago, que deu lugar ao palácio do governo ou a igreja da Matriz, que foi substituída pela catedral metropolitana -, e grande parte das novas construções públicas - como a Assembleia Legislativa, edificada sobre a antiga igreja da Misericórdia - e particulares. Do mesmo modo, também agora as escadarias - que se colocaram por sobre as antigas ladeiras - e os sucessivos aterros - que fizeram sumir as duas entradas de mar junto à colina, permitiram o início das obras do porto e novamente redesenharam toda a costa da cidade são testemunhas dessa nova paisagem, marcada primordialmente pela transformação. A avenida Jerônimo Monteiro, por sua vez, que abrigou grande parte dos mais importantes edifícios construídos na cidade e a primeira ligação, via ponte, da capital a Vila Velha, em 1928, são talvez, desse conjunto, os mais importantes símbolos. Eclética e burguesa, Vitória finalmente se consolida como a principal cidade do Estado, posto até então disputado com Cachoeiro de Itapemirim.
\end{abstract}

Tal fala assinala a origem e desenrolar destes empreendimentos, bem como a forma com que foram assimilados enquanto herança político-ideológica pelos sucessores de Muniz Freire. Soma-se a isso, grosso modo, o fato de que nem mesmo os mecanismos encontrados pelos próximos presidentes do Estado, para dar continuidade aos ideais de Saturnino de Brito e Freire, apresentaram considerável diferença em relação aos que foram empregues no início da República pelo então Presidente capixaba. Isso se deve, substancialmente, devido a forma com que estes se aproveitavam dos períodos de balança comercial favorável do café para, sem fugir da dependência deste produto, acumular o capital necessário ao financiamento das obras a posteriori. Logo, sentencia-se que o processo de modernização de Vitória trilhou percursos já conhecidos, seja pela manutenção desta herança político-ideológica, seja por este "trilhar" ter seguido à risca o peso do verbete ao se materializar nos demais projetos férreos responsáveis pela ligação dos diferentes pontos estaduais à cidade de Vitória e seu porto, fazendo jus a mais-valia da capital, pari passu alicerçava seu projeto de capitalidade e de reorganização territorial da economia. Noções que também já haviam sido expostas e defendidas por Muniz Freire.

\section{Considerações finais: revelando um projeto urbano} baseado em contradições e falsos problemas

No decorrer deste artigo, buscou-se expor as transformações ocorridas na cidade de Vitória no limiar do período republicano nacional, mais especificamente os planos e projetos desenvolvidos, e em parte aplicados, pelo Presidente do Estado Muniz Freire, como uma forma de empreendedorismo urbano permeado pelo ideal, ainda que implícito, de mercantilização da cidade. Essa fase, especialmente no que diz respeito ao seu primeiro mandato (1892-1896), apesar de não se limitar a ele, foi escolhida por se tratar de um momento de inflexão política nacional e, consequentemente, estadual, contando com a consolidação de grupos oligárquicos ligados ao setor primário e aos ideais positivistas, concomitante ao aumento da receita orçamentária capixaba, fruto, dentre outros elementos, da valorização de sua principal commodity: o cafés.

Desse modo, a excepcional conjuntura políticoeconômica da época, seus agentes e práticas estabelecidas no e pelo estado, referendaram o deflagrar de profundas transformações na Cidade Presépio, aproximando a "cidade desejada", uma referência urbana moderna de capitalidade, concatenada com o desenvolvimento que os poderes hegemônicos projetavam para o Espírito Santo, da "cidade possível", consubstanciada em parte pela aplicação, mesmo que paulatina, do Novo Arrabalde. A isso se soma o desenvolvimento de uma rede férrea em que "todos os caminhos" ligavam a Vitória, além das obras de modernização e expansão do porto local, as quais também contribuíram para que a cidade perdesse o dito "ar de atraso" para se lançar enquanto núcleo econômico.

Assim, visando concretizar tais ações, chamam atenção a forma como determinadas questões foram

5 Ainda cabem registrar outros eventos importantes nessa inflexão nacional e estadual, mas que não são propriamente abordados neste artigo, apesar de se encontrarem direta ou indiretamente vinculados aos debates firmados, como: a forma com que o coronelismo e a República se manifestaram no Espírito Santo; a forma como o trabalho e a terra se apresentavam e foram transformados nessa virada de século, do XIX para o XX, e; como esses diferentes fatores puderam contribuir para a tardia industrialização capixaba; dentre outros assuntos que merecem ser evidenciados em novos e verticalizados estudos. Logo, a supressão destes temas, contando ou não com seu tangenciamento no artigo, correspondem a escolhas argumentativas que se enquadrassem no debate proposto e nos limites de páginas que possuíamos para isso. Dessa forma, não se trata, necessariamente, de um juízo de valor sobre a preponderância que determinados eventos possam ter tido sobre outros. Ao mesmo tempo, tais escolhas abrem o precedente para que estes sejam abordados em outros escritos, vindo a complementar e/ou aprofundar o que aqui foi exposto. 
postas via discursos e práticas políticas que se iniciaram com Muniz Freire e aparentam ter permanecido na história capixaba como uma espécie de herança políticoideológica por ele deixada. Consequentemente, a análise dos discursos de Freire, identificando argumentos e justificativas que embasariam tal herança e sua reiteração futura, na medida em que não se observam mudanças nos rumos capixabas por ele delineados, soma-se às suas práticas e à de demais mandatos no período republicano, possibilitando depreender, mesmo que em alguns casos implicitamente, como tais questões foram concebidas, executadas e travestidas para o grande público enquanto falsos problemas, assumindo o papel de legitimadoras dos processos de desenvolvimento e modernização da capital. Processos estes que traziam em seu bojo o ideal de reorganização territorial da economia capixaba pautada na capitalidade de Vitória, um espaço preteritamente incumbido de referenciar os aspectos políticos estaduais, mas que não contava com um notório viés econômico, ainda sob influência de outras regiões.

Logo, alguns destes aspectos, usados para amparar as transformações na então Cidade Presépio, foram sobrepesados por homens como Muniz Freire ao ponto de evidenciarem contradições tanto em seus argumentos, quanto em suas práticas. O sobrepeso concedido e as contradições identificadas, tratando Vitória a partir de um emaranhado de falsos problemas a serem resolvidos via "construção" de uma cidade que se almejava interpor ao "presépio", visavam legitimar processos de "embelezamento", racionalização e higienização urbanas. Nesta perspectiva, a paisagem identitária da capital foi desconsiderada, apresentando parcas e esparsas intervenções, normalmente atreladas a uma remodelação de espaços públicos e/ou a complementariedade das obras portuárias e férreas que desembocariam em suas novas áreas. No mais, não só o aspecto infraestrutural aparece como justificativa para que intervenções urbanísticas fossem realizadas, como, muitas vezes, surgia acompanhado de premissas demográficas, evidenciando o uso político de questões humanitárias. Sendo assim, tais questões, prementes no que se refere ao melhoramento urbano e das condições de vida dos habitantes de Vitória durante a Primeira República, independentemente de seu quantitativo, foram postas sob pretextos legítimos, porém, escamoteadores do interesse de se atingirem determinados objetivos oligárquicos que não correspondiam e/ou beneficiavam o grosso dos habitantes da capital. Por isso, é cabível defender a noção de que estes objetivos, os quais se tornar-se-iam cada vez mais claros no decorrer dos anos e dos mandatos de diferentes Presidentes do Estado, foram gestados por artifícios discursivos que podem ser apreendidos ao se notarem parte de suas contradições, sejam elas de cunho demográfico, sejam elas de cunho infraestrutural.

Com relação às contradições demográficas, elas se referem aos argumentos, utilizados como justificativas para as propostas de melhoramento urbano, de que a cidade apresentaria um substancial crescimento populacional no período, enquanto, na verdade, ela possuía uma população estimada facilmente comportável em seus limites. Ademais, Muniz Freire, em discurso, deixa patente sua preocupação com a ausência de trabalhadores para as obras interioranas, enquanto em outro momento alega haver abundância de mão de obra na capital, tornando plausível se pensar na subvenção e uso desse excedente de operários em outras regiões capixabas, algo que inibiria o referido crescimento demográfico anteriormente explicitado. Nessa lógica, cabe registrar que tais práticas, como as possíveis subvenções, eram medidas razoáveis em termos de políticas públicas em um momento de transição do trabalho escravo para o assalariado (vide imigração europeia e demais casos que ocorreram no Brasil). Completam o raciocínio a respeito dessa aparente contradição, a capacidade de Muniz Freire de planejar determinadas ações, até certo ponto, inovadoras para o período, tornando ainda mais plausível que este tivesse pensado em tais condições, não fossem outros interesses.

No que se refere às contradições infraestruturais, essas correspondem a, ao menos, dois processos. 0 primeiro se vincula às desapropriações desencadeadoras de uma crise habitacional na Cidade Presépio, as quais conduziram o governo a iniciativa de se construírem casas populares, para remediar as consequências de seus atos. Essas, erigidas em pontos distantes em Vitória, trazem à tona questionamentos sobre até onde tal iniciativa se constituiu em equívoco, ou astuciosa intervenção, tendo em vista o estranhamento causado por tais ações em um período no qual políticos como Muniz Freire e os demais Presidentes do Estado eram reconhecidos pelo planejamento prévio quanto a suas práticas e os possíveis impactos no orçamento, normalmente pensados em meio aos períodos de "diástole" dos preços do café. Logo, a despeito de equívoco, tal ocorrência aparenta ser mais uma faceta dos falsos problemas propagados, objetivando afastar determinados grupos sociais da então Cidade Presépio, algo que já vinha ocorrendo com a promulgação dos "códigos de posturas" e seu claro viés segregacionista, além de contribuir para a confecção de espaços de reserva via espraiamento do tecido urbano, conquistando 
e ocupando áreas mais distantes em e fora de Vitória.

O segundo processo se encontra articulado aos potenciais espaços de reserva que se somam aos criados pelo Novo Arrabalde, em meio a uma espécie de "especulação imobiliária primitiva". Essa se dava a partir das capciosas relações público-privadas existentes, ora regidas pelo Estado, idealizador do projeto e potencial promotor da renda transferida ao mercado de terras através de investimentos em infraestrutura e serviços urbanos, ora regidas por agentes privados, como a Companhia Brasileira Torrens. Inclui-se nisso o fato de que ambos eram os proprietários da maior parte dos loteamentos, ao ponto de se reservarem o direito de especular com eles, escolhendo o momento ideal para sua comercialização (FOLLADOR; FERREIRA, 2015).

Ainda no que diz respeito ao Projeto do Novo Arrabalde, nota-se a tensão existente entre o planejamento técnico de Saturnino de Brito, firmado na "cidade possível", e as ingerências oligárquicas representadas por Muniz Freire, firmadas na "cidade desejada". Dessa forma, a força dos discursos e desejos políticos, entremeados pelos interesses agroexportadores em Vitória e por um possível lobby de grupos, se retroalimentam em uma capital parcamente ocupada à época, cujos aspectos naturais não esboçavam vantagem para um projeto tão "ousado" como o de estender sua área urbana em seis vezes à área original. Consequentemente, estes corroboram alguns dos relatórios e relatos técnicos do período, dando a entender não se tratar de obras prioritárias, ao mesmo tempo em que representavam um exacerbado dispêndio de recursos públicos, os quais poderiam ser direcionados a outros setores e serviços. Fato é que, por mais que Muniz Freire tenha obtido sucesso em seus objetivos infraestruturais, mesmo que a longo prazo, e por mais que este tenha desarticulado e rearticulado as principais regiões produtoras do estado a seu bel-prazer, via desenvolvimento da circulação e transportes concomitante a implementação do Novo Arrabalde, não se deve esquecer os exageros e a inconsistência de suas justificativas, aqui tratadas como falsos problemas, dado que Vitória não se apresentava como um ponto chamariz para tudo o que foi realizado. $A$ isso pode se acrescentar que sua visão demonstra mais uma preocupação em dotar a cidade para o futuro almejado, fruto de um urbanismo oligárquico, exercício especulatório deveras incerto, do que necessariamente se solucionar os problemas por ela apresentados.

Por outro lado, parcerias como a observada entre o Estado e a Companhia Brasileira Torrens, apesar do planejamento e coordenação de suas atividades, não deixam de configurar uma atividade de risco. Isto se deve em razão de seu empreendedorismo urbano se concretizar, em parte, via desenvolvimento dos espaços de reserva, levando a cabo a mercantilização da cidade através da especulação com e em locais específicos, a fim de atrair as demais facetas do capital privado naquilo que poderá (ou não) proporcionar uma futura rentabilidade aos investimentos. Sendo assim, tais práticas reiteram a visão de um embrionário ajuste espacial, por mais que se dê em uma fase de pré-capitalismo industrial brasileiro e, consequentemente, capixaba (HARVEY, 2006).

Nesta acepção, a ideia de um rudimentar ajuste espacial, em curso no Espírito Santo ao longo da Primeira República, esboça sua plausibilidade na medida em que não se restringe apenas à produção do espaço em Vitória, criando e relocalizando pontos a serem explorados economicamente e que culminariam em sua plena capitalidade, mas também por se considerar a reorganização territorial da economia que vem em seu encalço, imposta e verificável no Espírito Santo desde então, tendo a antiga Cidade Presépio por polo. Essa, por sua vez, demonstra os impactos que a maisvalia da capital teve sobre as demais regiões, em grande medida negativos em termos de aprofundamento das assimetrias espaciais, tendo em vista a relação desigual que se estabeleceria em prol de Vitória. Ademais, cabe registrar que essas mesmas assimetrias, verificáveis entre a capital e o interior do estado, também foram gestadas internamente à cidade, a partir de suas novas áreas, aglutinadoras de intervenções em detrimento do antigo centro urbano local.

Por fim, é inegável que houve ganhos infraestruturais e em termos de organização espacial para Vitória a partir da profusão de obras e rearranjos pelos quais foi submetida no decorrer da Primeira República e em momentos posteriores. Entretanto, a crítica que aqui se coloca diz respeito à forma como tais processos foram conduzidos, escamoteando uma mercantilização da cidade, focada, claramente, no atendimento aos interesses agroexportadores e de demais grupos específicos, como as companhias imobiliárias existentes e que surgiam à época. Isto posto, antecipase um comportamento público-privado que se tornaria corriqueiro no capitalismo contemporâneo, pari passu se conjuga uma lógica de mercado baseada em poderes hegemônicos e na sobreposição das possibilidades de melhoria urbana para o grosso de seus moradores e para o desenvolvimento da vida social - por mais que se tenha consciência de que tais princípios estivessem longe de serem pensados e aplicados enquanto teoria urbana naquele período. 


\section{Referências}

\section{Fontes Primárias}

BRITO, F. S. R. de (1996). Projeto de um novo arrabalde. Rio de Janeiro: Xerox do Brasil. Vitória: Arquivo Público do Estado do Espírito Santo. (Coleção Canaã, vol. 2).

ESPÍRITO SANTO (Estado) (1892). Presidente (1892-1896: Muniz Freire). Discurso Pronunciado pelo Exm. Sr. Dr. José de Mello Carvalho Moniz Freire Presidente do Estado do Espirito Santo Após sua promessa constitucional perante o Congresso Constituinte. Vitória: s/i.

ESPÍRITO SANTO (Estado) (1893). Presidente (1892-1896: Muniz Freire). Mensagem do Presidente do Estado do Espirito Santo Lida ao Congresso do mesmo Estado na sua sessão de instalação a 16 de Setembro de 1893. Vitória: s/i.

ESPÍRITO SANTO (Estado) (1894). Presidente (1892-1896: Muniz Freire). Mensagem lida pelo Exm. Sr. Presidente do Estado do Espirito-Santo, na instalação do Congresso Legislativo. Vitória: s/i.

ESPÍRITO SANTO (Estado) (1895). Presidente (1892-1896: Muniz Freire). Mensagem do Exm. Sr. Presidente do Estado do Espirito-Santo Lida na installação do congresso legislativo em 17 de setembro de 1895. Vitória: s/i.

ESPÍRITO SANTO (Estado) (1896). Presidente (1892-1896: Muniz Freire). Relatório apresentado pelo Exmo. Sr. José de Mello Carvalho Moniz Freire, Presidente do Estado do Espírito Santo, ao passar o Governo ao Exmo. Sr. Dr. Graciano dos Santos Neves, em 23 de maio de 1896. Vitória: s/i.

\section{Bibliografia}

ALMADA, V. P. F. de. (1993) Estudos sobre a estrutura agrária e cafeicultura no Espírito Santo. Vitória: SPDC/UFES. BITTENCOURT, G. (2006) História geral e econômica do Espírito Santo. Vitória: Multiplicidade.

BOLAFFI, G. (1979) Habitação e Urbanismo: o problema e o falso problema. In.: MARICATO, E. (Org.). A produção capitalista da casa (e da cidade) no Brasil industrial. São Paulo: Editora Alfa-Ômega.

CAMPOS JUNIOR, C. T. de. (1996) O novo Arrabalde. Vitoria: Prefeitura Municipal.

FERREIRA, G. L. (2016) A reinvenção da cidade: a transformação das ruas e o reordenamento da vida na cidade de Vitória/ES - 1890/1928. Tese (Doutorado em História Social das Relações Públicas) - Universidade Federal do Espírito Santo, Vitória.

; QUINTÃO L. do C.; ARAÚJO, T. M. de. (2018) Cidades e oligarquias: o caso de Vitória/ES na Primeira República. In.: http://www.periodicos.ufes.br/dimensoes/article/download/19353/13721 Acesso em: 20 abr. 2019.

FOLLADOR, K. J.; FERREIRA, G. L. (2015) Histórias paralelas: modernização e urbanismo nas cidades de Vitória e Rio de Janeiro. In.: RIBEIRO, L. C. M. et al. (Org.). Modernidade e Modernização no Espírito Santo. Vitória: Edufes. p. 63-100. FREITAS, J. F. B. (2004) Aterros e decisões políticas no município de Vitória: efeito cascata. In: VIII Seminário de História da Cidade e do Urbanismo. Anais do VIII Seminário de História da Cidade e do Urbanismo. Niterói: ARQ.URB/UFF, PPGG/ GEO/UFRJ, IPPUR/UFRJ e PROURB/FAU/UFRJ. v. 1. p. 1-17.

(2009) Port activities and landfills in Vitória (ES): choices and outcomes. In: International Sociological Association Reserach Committee 21: Sociology of Urban and Regional Development. Anais ISA2009-RC21: São Paulo Conference: Inequality, inclusion and sense of belonging. São Paulo: Centro de Estudos da Metrópole. v. 1. p. 1-1.

HARVEY, D. (2006) A produção capitalista do espaço. São Paulo: AnnaBlume.

MARCHESE, V. F. (2017) Muniz Freire e o Desenvolvimento Geográfico Desigual no Espírito Santo. A construção de uma herança político-ideológica no território capixaba. Dissertação (Mestrado em Geografia) - Universidade Federal do Espírito Santo, Vitória.

MENDONÇA, E. M. S. et al. (2009) (Orgs.). Cidade Prospectiva - o projeto de Saturnino de Brito para Vitória. Vitória: EDUFES e AnnaBlume.

FREITAS, J. F. B. (2012) Investimento e poder político. Prós e contras dos atributos de uma capital - Vitória, Estado do Espírito Santo, Brasil. In: http://www.ub.edu/geocrit/sn/sn-418/sn-418-55.htm Acesso em: 20 abr. 2019.

MENDONÇA, M. C. (2014) A modernização do atraso: os fundamentos da urbanização de Vitória 1889-1930. Dissertação (Mestrado em Geografia) - Universidade Federal do Espírito Santo, Vitória.

(2013) Atraso regional e discurso político no Espírito Santo republicano. In.: Revista Geografares, n 15, p.

68-97, dez.

MONTEIRO, P. R. (2008) Vitória: Cidade e Presépio: os vazios visíveis da capital capixaba. São Paulo: Annablume, 2008. 
PALACIOS, W. D. C. (2007) A expansão dos espaços periféricos em Vitória durante o processo de urbanização na Primeira República (1889-1930). Dissertação (Mestrado em História Social das Relações Políticas) - Universidade Federal do Espírito Santo, Vitória.

PRODANOV, C. C.; FREITAS, E. C. de. (2013) Metodologia do trabalho científico: métodos e técnicas da pesquisa e do trabalho acadêmico. Novo Hamburgo: Feevale.

QUINTÃO, L. do C. (2008) A interiorização da capital pela estrada de ferro Sul do Espírito Santo. Dissertação (Mestrado em História Social das Relações Políticas) - Universidade Federal do Espírito Santo, Vitória.

(2015) Modernização urbana na Belle Époque capixaba: revisitando o Novo Arrabalde. In.: RIBEIRO, L. C. M. et al. (Orgs.). Modernidade \& Modernização no Espírito Santo. Vitória: EDUFES.

RAFFESTIN, C. (2011) Por uma Geografia do Poder. São Paulo: Editora Ática.

ROSTOLDO, J. P. (2011) A cidade desejada e a cidade possível: a construção da urbe republicana. In.: http://www. snh2011.anpuh.org/resources/anais/14/1300043050_ARQUIVO_Acidadedesejadaeacidadepossivel1.pdf Acesso em: 20 abr. 2019.

SALETTO, N. (1996) Trabalhadores nacionais e imigrantes no mercado de trabalho do Espírito Santo (1888-1930). Vitória: EDUFES.

SANTOS, E. F. dos. (2012) José de Melo Carvalho Muniz Freire. Coleção Memória do Desenvolvimento do Espírito Santo - Grandes Nomes. Vitória: Espírito Santo em Ação.

(2005) Vias de comunicação, conquista territorial e colonização estrangeira no Espírito Santo do séc. XIX: a gênese do pensamento político capixaba. In.: http://www.periodicos.ufes.br/dimensoes/article/view/2422/1918 Acesso em: 20 abr. 2019.

SEABRA, O. C. de L. (1987) O meandro dos rios nos meandros do poder: o processo de valorização dos rios e das várzeas do Tietê e do Pinheiros na cidade de São Paulo. Tese (Doutorado em Geografia Humana) - Universidade de São Paulo, São Paulo.

SUETH, J. C. R.; FRANCO, S. P. (2005) A dependência do Espírito Santo entre três mandatos e duas políticas: as administrações Moniz Freire e Jerônimo Monteiro. In.: Revista Ágora, Vitória, nº 2, p. 1-31. 